\title{
PIK3CA mutations are a predictor of docetaxel plus epirubicin neoadjuvant chemotherapy clinical efficacy in breast cancer
}

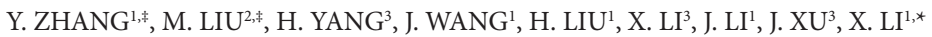 \\ ${ }^{1}$ Department of General Surgery, General Hospital of Chinese People's Liberation Army, 28 Fuxing Rd, Beijing 100853, China; ${ }^{2}$ Department of \\ Pathology, General Hospital of Chinese People's Liberation Army, 28 Fuxing Rd, Beijing 100853, China; ${ }^{3}$ SurExam Bio-Tech Co. Ltd., Guangzhou \\ 510663, China
}

*Correspondence:2468LI@sina.com, gangyu@sina.cn

${ }^{*}$ Contributed equally to this work.

Received September 18, 2013 / Accepted January 2, 2014

\begin{abstract}
This study proposed to investigate the relationship of PIK3CA somatic mutations, the most common activating mutations in human breast cancer (BC), and the efficacy of neoadjuvant chemotherapy (NCT).Using a novel liquidchip technology, PIK3CA DNA somat ic mutations and HER2, PTEN, EGFR mRNA expression profiles were analyzed in formalin fixed paraffin embedded samples of 93 BC patients treated with epirubicin plus docetaxel NCT.PIK3CA mutations were found in 30 patients (32.3\%), in which the point mutations of E542K, E545K, H1047L and H1047R were 4.3, 9.7, 4.3 and 14.0\% respectively. The PIK3CA mutations were significantly associated with patients' clinical response; 27 of 30 PIK3CA mutated patients had either a partial or complete response $(\mathrm{p}=0.002)$. Multivariate analysis further confirmed that, after adjustments for age, disease stages and NCT cycles, PIK3CA was associated with clinical response (Odds Ration 0.126, 95\% CI [0.029, 0.691]). However, there was no significant difference between PIK3CA mutations in pathological complete response (pCR, 7/92) and non-pCR group. Furthermore, no EGFR, KRAS and BRAF mutations were detected in any of the 93 samples.Our data for the first time suggested that PIK3CA mutation status may be a predictor for better understanding clinical response to the combination of epirubicin and docetaxel NCT in patients with BC.
\end{abstract}

Key words: PIK3CA somatic mutation, NCT, breast cancer, epirubicin, docetaxel

Neoadjuvant chemotherapy (NCT) has become the standard treatment for locally advanced breast cancer. Reducing tumor volume promotes higher breast -conserving surgery rates [1]. In patients with objective clinical response (complete response and partial responses combined) and especially pathological clinical response (pCR), an increase in disease-free and overall survival rates has been reported [2]. However, only 3-30\% patients achieved a pCR after cytotoxic drug treatment and about 20\% did not response to NCT at all [3]. Distinguishing whether a patient would response to NCT could avoid ineffectual treatment and provide a better quality of life.

Docetaxel and epirubicin are the most common chemotherapy regimens in adjuvant and neoadjuvant treatments for breast cancer. The combination of epirubicin and docetaxel was reported as one of the most active and well-tolerated treatments for locally advanced breast cancer [4]. In our previous studies, we treated patients with locally advanced breast cancer with the docetaxel plus epirubicin regimen. The objective response (OR) rates were $60.7 \%$ and $90 \%$ after 2 or 4 cycles of NCT, respectively. After 2 to 6 cycles of NCT, the complete response (CR) rate and pCR rate were $13.4 \%$ and $9.8 \%$, respectively $[5,6]$.

HER2 has been associated with the outcome of patients treated with epirubicin -based adjuvant chemotherapy [7, 8]. Yao et al. found that HER2 negative breast tumors were more responsive to anthracycline-based neoadjuvant chemotherapy than HER2 positive tumors [9]. It is not clear whether downstream genes of HER2 have a correlation with the effect of docetaxel plus epirubicin regimen.

EGFR, KRAS and BRAF oncogenes, which are frequently observed in many cancers, are rarely reported in breast cancer in Caucasian patients [10]; however, the prevalence of these genes in Chinese patients was unknown. PIK3CA is the most frequently mutated gene in human breast cancers [11], 
and the mutation is observed in $20-40 \%$ of tumors [12]. The PIK3CA mutation hotspots are exons 9 and 20, corresponding to the helical (E542K and E545K) and kinase (H1047R and $\mathrm{H} 1047 \mathrm{~L}$ ) domains, respectively [13]. PTEN is a suppressor of phosphatidylinositol 3-kinase (PI3K) and loss of PTEN expression is one cause of PI3K pathway activation. PIK3CA mutations and PTEN loss have been associated with pathological and clinical characteristics such as ER status, HER2 status, metastasis and disease prognosis [14]. PI3K pathway activation (PTEN low expression and/or PIK3CA mutation) is a major marker of drug resistance to trastuzumab [15]. Other studies reported that patients with PIK3CA mutations or increased PI3K pathway activity had a significantly poorer survival rate despite treatment with adjuvant CEF chemotherapy (cyclophosphamide $600 \mathrm{mg} / \mathrm{m}^{2}$, epirubicin $60 \mathrm{mg} / \mathrm{m}^{2}$ and fluorouracil $600 \mathrm{mg} / \mathrm{m}^{2}$ ) and trastuzumab [16].

Table 1. Patient characteristics $(\mathrm{n}=93)$

\begin{tabular}{|c|c|c|}
\hline Characteristic & No. & $\%$ \\
\hline \multicolumn{3}{|l|}{ Age } \\
\hline Median (range), years & $47(25-71)$ & \\
\hline \multicolumn{3}{|l|}{ NAT treatment } \\
\hline Median (range), cycles & $3(1-6)$ & \\
\hline \multicolumn{3}{|l|}{ Stage } \\
\hline I & 3 & $3 \%$ \\
\hline II & 60 & $65 \%$ \\
\hline III & 28 & $30 \%$ \\
\hline IV & 1 & $1 \%$ \\
\hline Missing & 1 & $1 \%$ \\
\hline \multicolumn{3}{|l|}{ Tumor size } \\
\hline$<2 \mathrm{~cm}(\mathrm{~T} 1)$ & 4 & $4 \%$ \\
\hline $2-5 \mathrm{~cm}(\mathrm{~T} 2)$ & 65 & $70 \%$ \\
\hline$>5 \mathrm{~cm}(\mathrm{~T} 3)$ & 19 & $20 \%$ \\
\hline $\mathrm{T} 4$ & 5 & $5 \%$ \\
\hline \multicolumn{3}{|l|}{ Clinical nodal status } \\
\hline Negative & 29 & $31 \%$ \\
\hline Positive & 63 & $68 \%$ \\
\hline Missing & 1 & $1 \%$ \\
\hline \multicolumn{3}{|l|}{ Metastasis } \\
\hline Negative & 92 & $99 \%$ \\
\hline Positive & 1 & $1 \%$ \\
\hline \multicolumn{3}{|l|}{ Histologic Grade (SBR) } \\
\hline G1 & 1 & $1 \%$ \\
\hline G2 & 44 & $47 \%$ \\
\hline G3 & 25 & $27 \%$ \\
\hline Missing & 23 & $25 \%$ \\
\hline \multicolumn{3}{|l|}{ Tumor phenotype } \\
\hline Triple negative & 13 & $14 \%$ \\
\hline Luminal A & 33 & $35 \%$ \\
\hline Luminal B & 9 & $10 \%$ \\
\hline Only HER2 positive & 15 & $16 \%$ \\
\hline Missing & 23 & $25 \%$ \\
\hline
\end{tabular}

In this work, we sought to evaluate PIK3CA, as well as EGFR, KRAS and BRAF hotspot somatic mutations, and HER2, PTEN and EGFR mRNA expression profiles in patients with breast cancer and to correlate these results with NCT outcomes.

\section{Materials and methods}

Patients and neoadjuvant treatment. 93 women with histological diagnosis of invasive breast cancer of any clinical tumor stage who were scheduled for neoadjuvant therapy were enrolled (Table 1). A diagnosis of carcinoma was established through core needle biopsy of the primary tumor and palpable lymph nodes. The tumor phenotypes were determined according to clinicopathologic criteria recommended by the St Gallen panelists [17].

Patients with a primary inflammatory carcinoma or metastatic diseases were excluded. All patients had docetaxel plus epirubicin NCT and surgery in the General Hospital of Chinese People's Liberat ion Army between June 2005 and May 2010. Patients received treatment with docetaxel $\left(75 \mathrm{mg} / \mathrm{m}^{2}\right)$ and epirubicin $\left(75 \mathrm{mg} / \mathrm{m}^{2}\right)$ on once every 3 weeks after core needle biopsy. The median cycle of chemotherapy was 4 cycles (range, 2-6). All procedures were carried out with the prior informed consent of the patients according to the Chinese FDA. And the same period, we collected 31 specimens from the people who received the biopsy. These people were confirmed have no breast cancer after histological examination. (http://www.sda.gov.cn/WS01/CL0053/24473.html).

Assessment of response to neoadjuvant chemotherapy. Both the pathological and clinical assessment of response to NCT was taken. The clinical response was evaluated at the end of NCT and prior to definitive surgery on day 21 following the last cycle of chemotherapy. Clinical response was determined by the tumor diameter and the axillary node status and was classified as a complete response (CR), partial response (PR), stable disease (SD) or progressive disease (PD) according to standard International Union Against Cancer (UICC) criteria [18]. CR and PR were classified as the objective response group (OR), while SD and PD were classified as the no response group (NR). Pathological response was evaluated by residual invasive cancer cells in the surgical specimen as compared to the core needle biopsy before NCT. Pathological complete response (pCR) was estimated according to Kuerer et al. [19].

Specimen collection and gene assays. Tumor tissues collected by needle biopsy before NCT, which were formalin fixed and paraffin embedded (FFPE) were used for gene assays. Tumor genomic DNA from each formalin fixed tissue was extracted by the Maxwell system (Promega, GA, USA) and the concentration determined using the Nanodrop 1000 spectrophotometer (Thermo Scientific, USA). The mutation status of exons 18 to 21 of EGFR, exons 2 and 3 of KRAS, exon 15 of BRAF and exons 9 and 20 of PIK3CA were analyzed simultaneously by xTAG liquidchip technology (SurExam, Guangzhou, China) [20]. 


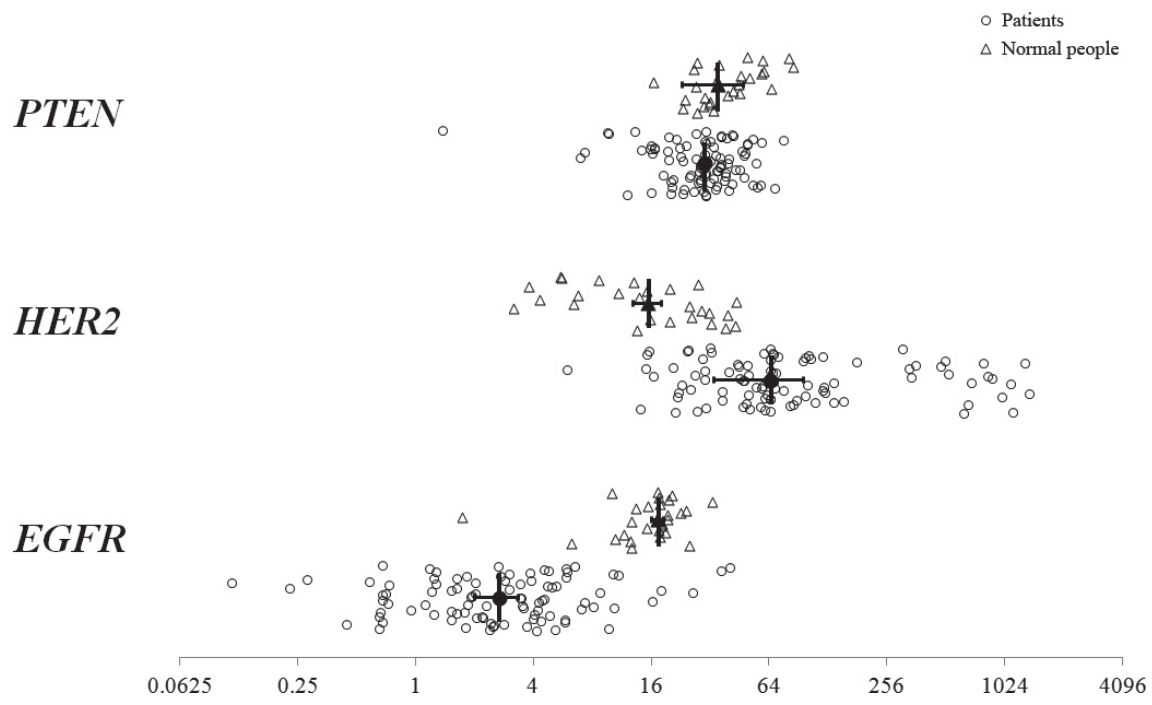

Figure 1. Scatter Plot of EGFR, HER2 and PTEN mRNA levels in 93 breast cancer specimens and 31 breast tissue specimens from normal people. Each dot represents a measurement of each patient. Long vertical bars represent median values and shorter vertical represent standard errors. The gene messenger RNA (mRNA) level was determined by branched DNA assay. The signal was normalized to reference genes. The horizontal was hundredfold and logarithmic (base 2).

Gene mRNA expression levels were analyzed simultaneously by multiplex branched DNA liquidchip (MBL) technology (SurExam, Guangzhou, China), a sandwich nucleic acid hybridization plat form in which targets are captured through cooperative hybridization of multiple probes in conjunction with a fluorescence signal amplification system, which has previously been shown to be a sufficient mRNA detection technology for FFPE specimens [21]. These specimens were analyzed for EGFR, HER2 and PTEN mRNA expression levels. For all samples, background signals were established as the blank control and subtracted from signals obtained in the presence of RNA samples. Signals of target genes were normalized against the geometric mean of five reference genes (ACTB, GAPDH, GUS, RPLP0 and TFRC). All data were represented as median fluorescence intensity (MFI). The normalized value of target mRNAs was evaluated by a formula, defined as the MFI of target mRNAs divided the geometric mean of the MFI of three housekeeping genes.

Statistical analysis. SAS 9.1.3 software (SAS Institute Inc, NC, USA) was used to evaluate the correlation between gene status and response to epirubicin plus docetaxel NCT. Comparisons between qualitative variables were analyzed using Mann-Whitney U test, Spearman rank correlation test and Fisher's exact test. Binary multivariate logistic regression was used to assess adjusted odds ratio (adjusted by age, stage and NCT cycles) with clinical response and pathological response. All $p$ values were two-sided, and a p value of less than 0.05 was considered statistically significant.

\section{Results}

EGFR, HER2 and PTEN mRNA expression patterns. EGFR, HER2 and PTEN mRNA expression levels were de- termined in all 93 samples. The median levels of expression of EGFR, HER2 and PTEN were 0.0262, 0.6426 and 0.3001 respectively in patients. And the median levels of expression of EGFR, HER2 and PTEN were 0.1732, 0.1536 and 0.3480 respectively in normal people. Mann Whitney U test show there was significant difference between patients and normal people in levels of expression of 3 genes (Table 2). The mRNA levels of EGFR and HER2 were extraordinarily high in some samples. In contrast, PTEN showed a very compact expression pattern: most were in the range of 0.1-0.6 (Figure 1).

EGFR, KRAS, BRAF and PIK3CA mutation status. EGFR, KRAS, BRAF and PIK3CA mutations were analyzed in all 93 tumor samples. No mutations were detected in EGFR, KRAS or BRAF. The mutation rate of PIK3CA was $32.3 \%$ (30/93). Mutation rates of E542K, E545K, H1047L and H1047R were 4.3, 9.7, 4.3 and $14.0 \%$ respectively. The PIK3CA mutation status in 31 normal people were also tested, Mutation rates of E542K, E545K, H1047L and H1047R were 0.0, 3.2, 3.2 and $3.2 \%$ respectively. The mutation rates of PI3KCA in normal people seemed like lower than patients, but had not reach the significance. (Table 3). No simultaneous mutation was detected. More PIK3CA mutations were found in lymph node

Table 2. EGFR, HER2 and PTEN expression in 93 Chinese patients with breast cancer and 31 Chinese Normal people

\begin{tabular}{lcccc}
\hline Gene & mRNA Expression & & [median(Q25-Q75) & \multirow{2}{*}{$\begin{array}{c}\text { P value } \\
\text { (Mann-Whitney U) }\end{array}$} \\
\cline { 2 - 3 } EGFR & $0.0262(0.0144-0.0476)$ & & $0.1732(0.1244-0.1924)$ & $<0.001$ \\
HER2 & $0.6426(0.3627-1.2088)$ & & $0.1536(0.0665-0.2947)$ & $<\mathbf{0 . 0 0 1}$ \\
PTEN & $0.3001(0.2183-0.3816)$ & $0.3480(0.2741-0.5251)$ & $\mathbf{0 . 0 0 9}$ \\
\hline
\end{tabular}


Table 3. PIK3CA mutation status in 93 Chinese patients with breast cancer and 31 Chinese Normal people

\begin{tabular}{|c|c|c|c|c|c|}
\hline \multirow{2}{*}{ Gene } & \multicolumn{2}{|c|}{ Patients $(\mathrm{N}=93)$} & \multicolumn{2}{|c|}{ Normal people $(\mathrm{N}=31)$} & \multirow{2}{*}{$\begin{array}{c}\text { P value } \\
\text { (Fisher's exact test) }\end{array}$} \\
\hline & No. of mutation & Percentage (\%) & No. of mutation & Percentage (\%) & \\
\hline PIK3CA exon 9 & 13 & 14 & 1 & 3.2 & 0.186 \\
\hline E542K & 4 & 4.3 & 0 & 0 & 0.571 \\
\hline E545K & 9 & 9.7 & 1 & 3.2 & 0.449 \\
\hline PIK3CA exon 20 & 17 & 18.3 & 2 & 6.5 & 0.153 \\
\hline H1047L & 4 & 4.3 & 1 & 3.2 & 1.000 \\
\hline H1047R & 13 & 14 & 1 & 3.2 & 0.186 \\
\hline
\end{tabular}

negative $(\mathrm{p}=0.0339)$ and low histological grade $(\mathrm{p}=0.0498)$ breast cancer (Table 4 ).

Neoadjuvant treatment response. Both the pathological and clinical assessment of response to NCT was taken successfully on 92 patients. For 1 of 93 patients, no response data were available. The OR was observed in 63 patients $(68.5 \%)$ treated with NCT. The CR rate was $28.3 \%$ (26/92) and the pCR rate was $7.6 \%$ (7/92). Progressive disease was observed in six patients $(6.5 \%)$.

Clinical and gene characteristics and their relationship with NCT response. We evaluated the association between NCT response, patient characteristics, histology and gene patterns (HER2, EGFR, PTEN mRNA expression and PIK3CA mutation). The results of univariate analysis showed patient's age, clinica $1 \mathrm{~T}$ status, nodal status, stage, chemotherapy cycles and PIK3CA mutation were associated with clinical response to NCT (Table 5). Clinical response was more likely in younger patients, small tumors, nodal negative, early stage ones and patients with PIK3CA mutation. PIK3CA exon 9 and exon 20 mutations had a tendency to be associated with clinical response to NCT respectively $(\mathrm{p}=0.056$ and 0.052 ) (Table 6). However, only patient's age and chemotherapy cycles were correlated with pathological response. Multivariate analyses for clinical and pathological response were done using the mutation status of PIK3CA, expression levels of HER2, EGFR, and PTEN, and age, stage, and number of NCT cycles as covariates. The significant association between outcome and PIK3CA mutations was

Table 4. Correlation between PIK3CA mutation and patient characteristics

\begin{tabular}{lcc}
\hline Patient characteristics & $\mathrm{r}$ & $\mathrm{p}$ value \\
\hline Age & 0.04131 & 0.7040 \\
NCT treatment & -0.09195 & 0.3860 \\
Stage & -0.19852 & 0.0592 \\
Tumor size & -0.14733 & 0.1611 \\
Clinical nodal status & -0.22266 & $\mathbf{0 . 0 3 3 9}$ \\
Metastasis & -0.07292 & 0.4897 \\
Histologic Grade & -0.23710 & $\mathbf{0 . 0 4 9 8}$ \\
Tumor phenotype & -0.00919 & 0.9403 \\
\hline
\end{tabular}

$\mathrm{r}$, Spearman rank correlation coefficient confirmed in multivariate analyses (Table 7). Compared with wild types, PIK3CA mutations were significantly associated with higher clinical response, whereas no significant difference in pathological response was seen.

Table 5. Univariate analysis of predictive factor of NCT response

\begin{tabular}{lccccc}
\hline \multirow{2}{*}{ Characteristics } & \multicolumn{2}{c}{ clinical response } & & \multicolumn{2}{c}{ pathological response } \\
\cline { 2 - 3 } \cline { 6 - 7 } & $\mathrm{r}$ & p value & & $\mathrm{r}$ & p value \\
\hline Age & -0.29853 & $\mathbf{0 . 0 0 4 7}$ & & 0.25644 & $\mathbf{0 . 0 1 9 3}$ \\
Chemotherapy cycles & 0.22014 & $\mathbf{0 . 0 3 6 0}$ & & 0.25251 & $\mathbf{0 . 0 3 7 8}$ \\
Clinical T status & -0.31302 & $\mathbf{0 . 0 0 2 4}$ & & 0.1904 & 0.0756 \\
Clinical nodal status & -0.25728 & $\mathbf{0 . 0 1 3 8}$ & & 0.07486 & 0.4908 \\
Stage & -0.35378 & $\mathbf{0 . 0 0 0 6}$ & & 0.10699 & 0.3240 \\
Histologic Grade (SBR) & -0.27171 & $\mathbf{0 . 0 0 4 7}$ & & -0.08164 & 0.5179 \\
Tumor phenotype & 0.17841 & 0.1425 & & -0.06611 & 0.6448 \\
HER2 exp & 0.09809 & 0.3577 & & 0.00914 & 0.9388 \\
EGFR exp & -0.19635 & 0.0636 & & 0.10524 & 0.3378 \\
PTEN exp & -0.17764 & 0.0921 & & 0.15061 & 0.1663 \\
PIK3CA mut & 0.27931 & $\mathbf{0 . 0 0 7 3}$ & & 0.12453 & 0.2505 \\
\hline
\end{tabular}

$\mathrm{r}$, Spearman rank correlation index; exp, expression; mut, mutation status.

Table 6. Fisher's exact test of predictive factor of NCT response

\begin{tabular}{|c|c|c|c|c|c|c|}
\hline \multirow{2}{*}{ Characteristics } & \multicolumn{3}{|c|}{ clinical response } & \multicolumn{3}{|c|}{ pathological response } \\
\hline & OR & NR & $\mathrm{p}$ value & $\mathrm{pCR}$ & non-pCR & $\mathrm{p}$ value \\
\hline Tumor phenotype & & & 0.913 & & & 0.186 \\
\hline triple negative & 8 & 5 & & 1 & 12 & \\
\hline non- triple negative & 33 & 18 & & 0 & 57 & \\
\hline PIK3CA exon 9 & & & 0.056 & & & 0.081 \\
\hline Mutation & 12 & 1 & & 0 & 13 & \\
\hline non-mutation & 51 & 28 & & 7 & 73 & \\
\hline PIK3CA exon 20 & & & 0.052 & & & 0.330 \\
\hline Mutation & 15 & 2 & & 1 & 16 & \\
\hline non-mutation & 48 & 27 & & 6 & 70 & \\
\hline PIK3CA & & & 0.002 & & & 0.422 \\
\hline Mutation & 27 & 3 & & 1 & 29 & \\
\hline non-mutation & 36 & 26 & & 6 & 57 & \\
\hline
\end{tabular}

OR, objective response; NR, no response; pCR, pathological complete response. 
Table 7. Multivariate logistic regression analysis of factors predictive of NCT response

\begin{tabular}{|c|c|c|c|c|c|c|}
\hline \multirow{2}{*}{ Characteristics } & \multicolumn{3}{|c|}{ Clinical response } & \multicolumn{3}{|c|}{ Pathological reponse } \\
\hline & OR & $95 \% \mathrm{CI}$ & $\mathrm{p}$ value & OR & $95 \% \mathrm{CI}$ & $\mathrm{p}$ value \\
\hline PIK3CA mut & 0.126 & $(0.029,0.691)$ & 0.0170 & 1.156 & $(0.370,3.616)$ & 0.8029 \\
\hline HER2 exp & 0.708 & $(0.194,2.581)$ & 0.6007 & 0.830 & $(0.284,2.422)$ & 0.7328 \\
\hline PTEN exp & 0.944 & $(0.259,3.439)$ & 0.9302 & 2.278 & $(0.750,6.918)$ & 0.1465 \\
\hline EGFR exp & 1.618 & $(0.454,5.773)$ & 0.4584 & 1.050 & $(0.347,3.180)$ & 0.9306 \\
\hline
\end{tabular}

OR, odds ratio

\section{Discussion}

In this study, the prevalence of EGFR, KRAS, BRAF and PIK3CA somatic mutations in tumors of 93 Chinese breast cancer patients was assayed and analyzed. No activating mutation was detected on EGFR, KRAS and BRAF in this study. This is consistent with the low mutation rate reported in Caucasian cancer patients [10]. Teng et al. found $11.4 \%$ $(8 / 70)$ triple negative (i.e., negative for estrogen receptor, progesterone receptor and Her2/neu) breast cancer patients in Singapore carried EGFR mutations [22]. The somatic mutations of EGFR, KRAS and BRAF might more frequent in triple negative breast cancer in East Asia patients. However, there were only $12 \mathrm{t}$ riple negative breast cancer tumors in this study. Moreover, the mutation rate of PIK3CA (35.1\%) was similar to that in Caucasian cancer patients (26-47.4\%) and more PIK3CA mutations were detected in node negative tumors [23].

Simultaneous KRAS/BRAF mutations and PIK3CA mutations were found in gynecological neoplasms (ovarian cancer and endometrial cancer) [24], which were not detected in breast cancer in this study. A novel branch DNA technology was used to detect the mRNA level of the genes. The quantitative and normalized results reflected a different expression pat tern between EGFR, HER2 and PTEN genes.

EGFR and HER2 gene expression had greater variability, which might be the results of large varieties of their molecular subtypes in these samples. Seventeen (18.3\%) samples with particularly high HER2 expression (normalized value $>2$ ) could be indicative of HER2 gene amplificat ion (10-20\%) [25]. In this study we did not test the consistency of the branch NDA technology with fluorescent in situ hybridization (FISH).

We evaluated the response to NCT in 92 breast cancer patients. The OR rate was $68.5 \%$, with a complete pathological response in $7.6 \%$ of patients. The OR was slightly lower than previously reported by Brazilian researchers using a similar chemotherapy scheme, while the pCR rate was higher in our study [26]. However, the pCR was still much lower than 15\%, which was reported recently in a pooled analysis [27]. This discordant result might be attributed to the differences of patient characteristics.

Previous researchers found that PIK3CA mutation was a major predictor of improved prognosis and drug resistance to trastuzumab $[14,15]$. PIK3CA mutation was considered to be an important gene variation in breast cancer due to its high mutation rate. We found a correlation between PIK3CA mutation and the clinical response to epirubicin plus docetaxel NCT. Breast cancer is a complex group with multiple molecular subtypes [28], and patients with distinct breast cancer subtypes respond to NCT differently [27]. PIK3CA mutation may serve as a predictor of a breast cancer subtype which is sensitive to epirubicin plus docetaxel.

Results in this study also showed that both exon 9 and exon 20 tended to be associated with clinical response, although this did not reach statistical significance. It's controversial whether the prognostic value of PIK3CA exon 9 and exon 20 mutations are equivalent $[14,29]$. However, PIK3CA mutations were often considered together in clinical research. Some studies reported the same predictive value of trastuzumab resistance between PIK3CA exon 9 and exon 20 mutations [30]. We found no difference between PIK3CA exon 9 and exon 20 mutations as predictors of NCT response.

We did not find any correlation between the genes studied and pCR in this study. A recent report showed that pCR was a suitable surrogate end point for patients with luminal B/HER2-negative, HER2-positive (nonluminal), and triple -negative disease, but not for those with luminal B/HER2positive or luminal A tumors [27]. On the other hand, gene status may be distinct in these subtypes. Consequently, predictive biomarker research design should take patient subtypes into account, and the pCR end point should be analyzed with subtypes for which $\mathrm{pCR}$ is shown to have prognostic value.

In conclusion, this study confirms the high prevalence of PIK3CA mutations in Chinese breast cancer. The PIK3CA mutation is a potential predictive marker for clinical response of epirubicin plus docetaxel neoadjuvant chemotherapy. The independent predictive value of PIK3CA mutation status in breast cancer patients treated with epirubicin plus docetaxel neoadjuvant chemotherapy should be confirmed in larger randomized prospective clinical trials.

Acknowledgments: We thank Keke Tang for data statistics; Gang Yu, Jiaying $\mathrm{He}$, Zhifeng $\mathrm{Xu}$ and Jiancheng Luo for their support in specimen collection and detection; and Dr. Lifen RenHeidenreich for her editorial assistance. This work was supported by Grant No. 81372386 with National Natural Science Foundation of China. 


\section{References}

[1] BERIWAL S, SCHWARTZ GF, KOMARNICKY L, GARCIAYOUNG JA. Breast-conserving therapy after neoadjuvant chemotherapy: long-term results. Breast J 2006; 12: 159-164. http://dx.doi.org/10.1111/j.1075-122X.2006.00225.x

[2] ABRIAL SC, PENAULT-LLORCA F, DELVA R, BOUGNOUX P, LEDUC B ET AL. High prognostic significance of residual disease after neoadjuvant chemotherapy: a retrospective study in 710 patients with operable breast cancer. Breast Cancer Res Treat 2005; 94: 255-263. http://dx.doi.org/10.1007/s10549005-9008-8

[3] TEWARI M, KRISHNAMURTHY A, SHUKLA HS. Predictive markers of response to neoadjuvant chemotherapy in breast cancer. Surg Oncol 2008; 17: 301-311. http://dx.doi. org/10.1016/j.suronc.2008.03.003

[4] HIRANO A, SHIMIZU T, IMAMURA H, WATANABE O, KINOSHITA J ET AL. The combination of epirubicin plus docetaxel as neoadjuvant chemotherapy in locally-advanced breast cancer. Anticancer Res2006; 26: 581-584.

[5] LI XR, LIU M, ZHANG YJ, WANG JD, ZHENG YQ ET AL. ER, PgR, HER-2, Ki-67, topoisomerase IIalpha, and nm23-H1 proteins expression as predictors of pathological complete response to neoadjuvant chemotherapy for locally advanced breast cancer. Med Oncol 2011; 28 Suppl 1: S48-54. http:// dx.doi.org/10.1007/s12032-010-9693-y

[6] LI XR, WANG JD, ZHANG YJ, KONG QL, MA B ET AL. [Effects of neoadjuvant chemotherapy of docetaxel combined with and epirubicin or pirarubicin on breast cancer: clinical analysis of 160 cases]. Zhonghua Yi Xue Za Zhi 2009; 89: 87-90.

[7] HERTEL PB, TU D, EJLERTSEN B, JENSEN MB, BALSLEV E ET AL. TIMP-1 in combination with HER2 and TOP2A for prediction of benefit from adjuvant anthracyclines in highrisk breast cancer patients. Breast Cancer Res Treat 2012; 132: 225-234. http://dx.doi.org/10.1007/s10549-011-1896-1

[8] EJLERTSEN B, JENSEN MB, NIELSEN KV, BALSLEV E, RASMUSSEN BB ET AL. HER2, TOP2A, and TIMP-1 and responsiveness to adjuvant anthracycline-containing chemotherapy in high-risk breast cancer patients. J Clin Oncol 2010; 28: 984-990. http://dx.doi.org/10.1200/JCO.2009.24.1166

[9] YAO L, LIU Y, LI Z, OUYANG T, LI J ET AL. HER2 and response to anthracycline-based neoadjuvant chemotherapy in breast cancer. Ann Oncol 2011; 22: 1326-1331. http://dx.doi. org/10.1093/annonc/mdq612

[10] JACOT W, LOPEZ-CRAPEZ E, THEZENAS S, SENAL R, FINA F ET AL. Lack of EGFR-activating mutations in European patients with triple-negative breast cancer could emphasise geographic and ethnic variations in breast cancer mutation profiles. Breast Cancer Res 2011; 13: R133. http:// dx.doi.org/10.1186/bcr3079

[11] SHAH SP, ROTH A, GOYA R, OLOUMI A, HA G ET AL. The clonal and mutational evolution spectrum of primary triplenegative breast cancers. Nature 2012; 486: 395-399260 .

[12] STEMKE-HALE K, GONZALEZ-ANGULO AM, LLUCH A, NEVE RM, KUO WL ET AL. An integrative genomic and proteomic analysis of PIK3CA, PTEN, and AKT mutations in breast cancer. Cancer Res 2008; 68: 6084-6091. http://dx.doi. org/10.1158/0008-5472.CAN-07-6854

[13] BACHMAN KE, ARGANI P, SAMUELS Y, SILLIMAN N, PTAK J ET AL. The PIK3CA gene is mutated with high frequency in human breast cancers. Cancer Biol Ther 2004; 3: 772-775. http://dx.doi.org/10.4161/cbt.3.8.994

[14] CIZKOVA M, SUSINI A, VACHER S, CIZERON-CLAIRAC G, ANDRIEU C ET AL. PIK3CA mutation impact on survival in breast cancer patients and in ERalpha, PR and ERBB2based subgroups. Breast Cancer Research 2012; 14: R28. http://dx.doi.org/10.1186/bcr3113

[15] PARK BH, DAVIDSON NE. PI3 kinase activation and response to Trastuzumab Therapy: what's neu with herceptin resistance? Cancer Cell. 2007; 12: 297-299. http://dx.doi. org/10.1016/j.ccr.2007.10.004

[16] JENSEN JD, KNOOP A, LAENKHOLM AV, GRAUSLUND M, JENSEN MB ET AL. PIK3CA mutations, PTEN, and pHER2 expression and impact on outcome in HER2-positive early-stage breast cancer patients treated with adjuvant chemotherapy and trastuzumab. Ann Oncol 2012; 23: 2034-2042. http://dx.doi.org/10.1093/annonc/mdr546

[17] GOLDHIRSCH A, WOOD WC, COATES AS, GELBER RD, THURLIMANN B ET AL. Strategies for subtypes-dealing with the diversity of breast cancer: highlights of the St. Gallen International Expert Consensus on the Primary Therapy of Early Breast Cancer 2011. Ann Oncol 2011; 22: 1736-1747. http://dx.doi.org/10.1093/annonc/mdr304

[18] HAYWARD JL, CARBONE PP, HEUSEN JC, KUMAOKA S, SEGALOFF A ET AL. Assessment of response to therapy in advanced breast cancer. Br J Cancer 1977; 35: 292-298. http://dx.doi.org/10.1038/bjc.1977.42

[19] KUERER HM, NEWMAN LA, SMITH TL, AMES FC, HUNT KK ET AL. Clinical course of breast cancer patients with complete pathologic primary tumor and axillary lymph node response to doxorubicin-based neoadjuvant chemotherapy. J Clin Oncol 1999; 17: 460-469.

[20] LI G, LUO X, HE J, ZHU Z, YU G ET AL. A novel liquidchip platform for simultaneous detection of 70 alleles of DNA somatic mutations on EGFR, KRAS, BRAF and PIK3CA from formalin-fixed and paraffin-embedded slides containing tumor tissue. Clin Chem Lab Med 2011; 49: 191-195. http://dx.doi.org/10.1515/CCLM.2011.040

[21] FLAGELLA M, BUI S, ZHENG Z, NGUYEN CT, ZHANG A ET AL. A multiplex branched DNA assay for parallel quantitative gene expression profiling. Anal Biochem 2006; 352: 50-60. http://dx.doi.org/10.1016/j.ab.2006.02.013

[22] TENG YH, TAN WJ, THIKE AA, CHEOK PY, TSE GM ET AL. Mutations in the epidermal growth factor receptor (EGFR) gene in triple negative breast cancer: possible implications for targeted therapy. Breast Cancer Res 2011; 13: R35. http:// dx.doi.org/10.1186/bcr2857

[23] KALINSKY K, JACKS LM, HEGUY A, PATIL S, DROBNJAK M ET AL. PIK3CA mutation associates with improved outcome in breast cancer. Clin Cancer Res 2009; 15: 5049-5059. http://dx.doi.org/10.1158/1078-0432.CCR-09-0632

[24] JANKU F, WHELER JJ, WESTIN SN, MOULDER SL, NAING A ET AL. PI3K/AKT/mTOR inhibitors in patients with breast 
and gynecologic malignancies harboring PIK3CA mutations. J Clin Oncol 2012; 30: 777-782. http://dx.doi.org/10.1200/ JCO.2011.36.1196

[25] OWENS MA, HORTEN BC, DA SILVA MM. HER2 amplification ratios by fluorescence in situ hybridization and correlation with immunohistochemistry in a cohort of 6556 breast cancer tissues. Clin Breast Cancer. 2004; 5: 63-69. http://dx.doi. org/10.3816/CBC.2004.n.011

[26] TIEZZI DG, ANDRADE JM, RIBEIRO-SILVA A, ZOLA FE, MARANA HR ET AL. HER-2, p53, p21 and hormonal receptors proteins expression as predictive factors of response and prognosis in locally 300 advanced breast cancer treated with neoadjuvant docetaxel plus epirubicin combination. BMC Cancer 2007; 7: 36. http://dx.doi.org/10.1186/1471-2407-736

[27] VON MINCKWITZ G, UNTCH M, BLOHMER JU, COSTA SD, EIDTMANN H ET AL. Definition and impact of pathologic complete response on prognosis after neoadjuvant chemotherapy in various intrinsic breast cancer subtypes. J Clin Oncol 2012; 30: 1796-1804304. http://dx.doi.org/ $\underline{10.1200 / \text { JCO.2011.38.8595 }}$

[28] CURTIS C, SHAH SP, CHIN SF, TURASHVILI G, RUEDA OM ET AL. The genomic and transcriptomic architecture of 2,000 breast tumours reveals novel subgroups. Nature 2012; 486: 346-352.

[29] BARBARESCHI M, BUTTITTA F, FELICIONI L, COTRUPI S, BARASSI F ET AL. Different prognostic roles of 308 mutations in the helical and kinase domains of the PIK3CA gene in breast carcinomas. Clin Cancer Res 2007; 13: 6064-6069. http://dx.doi.org/10.1158/1078-0432.CCR-07-0266

[30] KATAOKA Y, MUKOHARA T, SHIMADA H, SAIJO N, HIRAI M ET AL.ASSOCIATION BETWEEN GAIN-OFFUNCTION MUTATIONS IN PIK3CA AND RESISTANCE TO HER2-TARGETED AGENTS IN HER2-AMPLIFIED BREAST CANCER CELL LINES. Ann Oncol 2010; 21: 255-262. http://dx.doi.org/10.1093/annonc/mdp304 